\title{
MAINTAINING THE WELL-BEING OF AGEING POPULATION IN THE CZECH REPUBLIC
}

\author{
KATEŘINA GAWTHORPE ${ }^{\mathrm{a}, *}$, KAREL ŠAFR $^{\mathrm{b}}$ \\ xzimk04@gmail.com,karelsafr@gmail.com \\ a University of Economics in Prague, Faculty of Business Administration, Department of Managerial Economics, \\ W. Churchill Sq. 4, Prague, Czech Republic \\ b University of Economics in Prague, Faculty of Informatics and Statistics, Department of Demography, \\ W. Churchill Sq. 4, Prague, Czech Republic
}

\begin{abstract}
This study analyses the problem of ageing which is currently one of the biggest concerns for central authorities in the Czech Republic. The rapidly changing demographic structure has affected the fiscal policy framework. The focus here is on the economic impact of the ageing phenomenon with respect to the well-being of individuals in the Czech economy. The paper aims to reveal the size of technological progress but also government expenditures necessary to keep the current well-being unaltered to the dynamics of demographic prognosis. The applied method reposes upon a New Keynesian general equilibrium model. This model is disaggregated with the so-called bottom-up approach to capture the nuanced differences among three selected ageing cohorts.
\end{abstract}

\section{Key words}

ageing, Czech economy, general-equilibrium model

\section{JEL classification}

C61, J14

\section{Introduction}

Ageing phenomenon has worried Czech economy for years. Authors Babecky and Dybczak (2009) have already stressed this issue. Dozen years later the demographic prospects have improved only slightly. The combined Figure 1 documents the increase in the share of elderly projected for the year 2050 (darker columns) relatively to the demographic structure in 2018 (lighter columns).

The Pay-as-you-go (PAYG) is not a sustainable pension scheme for the Czech economy in the presence of ageing population. Increase in responsibility of agents over their own income during retirement has been viewed as a potential solution (see Babecky and Dybczak, 2009). These authors incentivize fiscal-policy makers to decrease fiscal-policy contribution to the pension system in order to motivate individuals to supply more labor and keep the economy more resilient towards the ageing phenomenon. Other authors Kilponen et al. (2006) find reduction in pension benefits as a preferable scenario relatively to a policy which incentivizes individuals to work for more years before retiring. The model of Braz et al. (2013) favors a policy mix instead of imposing a single policy reform.

The above-mentioned studies focus on finding the most suitable fiscal-policy measure. On the contrary, we measure the ageing problem from the standpoint of individuals. The present article questions the degree into which the altering demographic structure affects well-being of individuals. In detail, the model simulations aim to reveal the technology level necessary to keep up with the ageing trend should the well-being of individuals stay unaltered. Next, the model outcome discloses the level of government expenditure necessary to guarantee that individuals are not worse off in the presence of the demographic shifts. Following the studies 
of Fleurbaey (2009) and Benjamin et al. (2012) the well-being is measured as an additive utility function.

Figure 1: Share of individual ageing cohorts

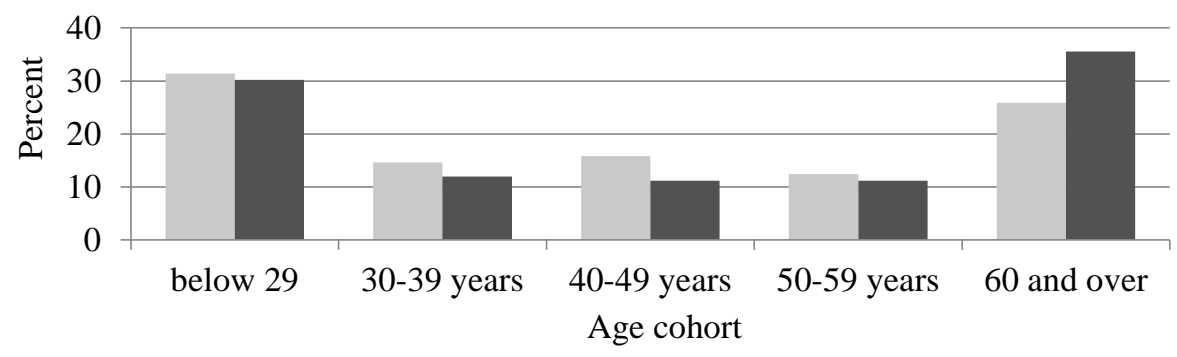

Source: the authors based on data from Eurostat.

The present article analyzes the impact of changing demographic structure on the well-being in the Czech economy with a New Keynesian computable general equilibrium model. This model is an extended DSGE model from Aliyev et al. (2014) originally developed for the purpose of the Czech Ministry of Finance. The benchmark model is subject to enhancement to account for the ageing issue. The model accounts for four types of households differing in age where the last cohort consists of retirees. The number of hours worked will depend on effectiveness measured for each of this household group. The new model also assumes existence of social security benefits and pensions. This modification affects government sector but also firms which has now the option to select from age-differentiated labor supply. The four cohorts of households will also differ in their consumption expenditures as well as different responsiveness of consumption to income changes.

The advantage of this modelling technique is its ability to capture complex economic structure. Ageing issue is not a straightforward problem with an easy diagnostic of its economic impact. Kilponen et al. (2006) discuss more pronounced impact of ageing on economy in a model which accounts for labor supply, wages and consumption. Omission of these interlinkages could then result in an undervaluation of the impact-evaluation of ageing problem.

Next, the overlapping generations model from Braz et al. (2013) assumes fraction of households to be Non-Ricardians. This simplification is very common for fiscal policy papers (see Aliyev et al., 2014; Roeger et al., 2008; Copaciu et al., 2015). Such assumption suggests for a fraction of population to spend all its income. Unfortunately, Coenen and Straub (2005) indicates a relatively small share of Non-Ricardian households counting to around 25 percent for the euro area. The study of Braz et al. (2013) proves difficulty to maintain the assumption of the rule-of-thumb consumers in a model which accounts for a consumption heterogeneity carried out by other attributes than income. For these reasons, the present model will evade the assumption about rule-of-thumb households. This article will instead incorporate sufficient income effect for consumption by introducing a nuanced method for derivation of the Euler equation.

This study starts with an outlie of the model. This section is followed by the description of selected parameters. Subsequent two sections describe simulation results. Conclusion summarizing the findings from the article is present at the end of this study.

\section{Model}

The presented model originates in the study of Aliyev et al. (2014). The benchmark model is extended to account for four age cohorts. Each cohort consists of a representative household with a main breadwinner who is 30-39 years old, 40-49 years old, 50-59 years old and older than sixty. To keep the analysis concise, we outline the derivation of equations which differ from the original study. 


\subsection{Household}

Households follow a modified version of the benchmark model from Aliyev et al. (2014). The overall size of population $P O P$ is assumed to stay constant. The population consists of four different age groups labeled in general as $r$. There coexist four household cohorts, the young household $y$, the middle-aged household $m$, the old household $o$ and the pensioners $p$. The demographic structure affects individual macroeconomic variables. Aggregation of these heterogenous variables accounting for different age groups necessitates multiplication of every variable $V A R_{t}^{r}$ for the age group $r$ with the absolute value of the variable's share in total population i.e.

$$
V A R_{t}=\left(\sum_{r=1}^{A} V A R_{t}^{r} \Omega^{r}\right) P O P,
$$

where $\sum_{r=1}^{A} \Omega^{r}=1$, capital $A$ stands for the share of various ageing groups $(y, o, m, p)$. The $V A R_{t}$ expression concerns consumption, labor supply, labor demand, wages and the overall welfare function.

A representative household of type $r \epsilon(y, o, m, p)$ maximizes its utility over consumption $C_{j, t}^{r}$ and labor supply $N_{j, t}^{r}$ i.e.

$$
E_{t} \sum_{n=0}^{\infty} \beta^{n} U_{j, t+n}=E_{t} \sum_{n=0}^{\infty} \beta^{n}\left\{\log \left(C_{j, t+n}^{r}-H_{j, t+n}^{r}\right)-\frac{\left(N_{j, t+n}^{r}\right)^{1+\psi_{N}}}{1+\psi_{N}}\right\},
$$

where the parameter $\beta$ stands for the discount factor, $H_{j, t}$ is the external habit formation and $\psi_{N}$ labels the inverse elasticity of labor supply; subject to the intertemporal budget constraint

$$
\begin{aligned}
& \left(1+\tau_{t}^{c}\right) P_{t}^{c} C_{j, t}^{r}+P_{t}^{I} I_{j, t}+P_{t} a\left(u_{j, t}\right) K_{j, t}^{s}+\frac{1}{R_{t}} B_{j, t+1}+\frac{1}{R_{t}^{*}+r p_{t}} S_{t} B_{j, t+1}^{*} \\
& =B_{j, t}+S_{t} B_{j, t}^{*}+\left(1-\tau_{t}^{k}\right)\left[R_{t}^{k} u_{j, t} K_{j, t}^{s}+Q_{t}\right]+\left[1-\tau_{t}^{w}-\tau_{t}^{s c}\right] W_{t}^{r}\left(\Lambda_{t}^{r}\right)^{g^{r}} N_{j, t}^{r}+ \\
& \tau_{t}^{b} W_{t}^{b, r}\left(N_{j, t}^{r}-L_{j, t}^{r}\right)+T R_{t}^{r}+P E N_{t}^{r} \text {. }
\end{aligned}
$$

The first term on the left-hand side of the budget constraint stands for the consumption expenditures increased for the value-added tax $\tau_{t}^{c}$; this term is followed by the investment expenditure $P_{t}^{I} I_{j, t}$. The next variable in the budget constraint is the capital stock $K_{j}^{s}$, which is multiplied by the capital adjustment costs $a\left(u_{j, t}\right)$ where $u_{j, t}=K_{j, t} / K_{j, t}^{S}$ is the utilization rate of capital $u_{j, t}$. The capital adjustment costs are an increasing convex function. The last two sources of expenditures are domestic and foreign bonds respectively $B_{j, t+1}, B_{j, t+1}^{*}$ with the interest rates $R_{t}, R_{t}^{*}$ and risk premium for holding foreign bonds $r p_{t}$.

A representative household generates income from bonds $B_{j, t}, B_{j, t}^{*}$, from return on capital $R_{t}^{k} u_{j, t} K_{j, t}^{s}$ but also from ownership of a company $Q_{t}$. The capital gains are subject to capital tax $\tau_{t}^{k}$. Households also participate in labor market where they earn wage $W_{t}^{r}$ reduced for income $\operatorname{tax} \tau_{t}^{w}$ and payment of social-security benefits $\tau_{t}^{S c}$. The labor income depends on the effective labor supply $\left(\Lambda_{t}^{r}\right)^{g^{r}} N_{j, t}^{r}$. $\Lambda_{t}^{r}$ reflects the age profile of labor productivity (See Babecký and Dybczak, 2009). Based on the specification of the budget constraint, we define the net wage as

$$
W_{t}^{n e t, r}=\left[1-\tau_{t}^{w}-\tau_{t}^{s c}\right] W_{t}^{r} .
$$

The aggregate labor supply consists of the differentiated labor supply for individual ageing groups:

$$
N_{t}=\left(\sum_{r=1}^{A} N_{t}^{r} \Omega^{r}\right) P O P .
$$

Unemployed households receive unemployment benefits, which size depends on the unemployment benefits rate $\tau_{t}^{b}$ set by government, wage bill $W_{t}^{b, r}$ and on the size of 
unemployment $N_{j, t}^{r}-L_{j, t}^{r}$. Finally, the last two potential sources of income originate in the form of pensions $P E N_{t}^{r}$ and other transfers $T R_{t}^{r}$ which include government transfers other than pensions or unemployment benefits. The differentiation of pensions into the four groups is important as households are classified into the individual age cohorts based on the age of the main breadwinner, each household might then contain a retiree.

The pensions depend on the replacement rate and on the average hourly wage multiplied by the average number of worked hours in the economy i.e.

$$
P E N_{t}^{r}=\operatorname{rep}_{t}\left[1-\tau_{t}^{w}-\tau_{t}^{s c}\right] W_{t}^{n e t} \mathrm{~N}_{t}
$$

or by other words, the replacement ratio is a share of average pension to average wage.

Despite, the resemblance between the utility function and the budget constraint in this model and the benchmark model, the models are derived with divergent procedures for obtaining first order conditions with respect to consumption.

It is possible to rewrite the budget constraint as a bundle of expenditures a household decides over as a matrix $\mathbb{Z}_{t}$ and the bundle of different sources of revenue as a matrix $\mathbb{R}_{t}$. Given the assumed equality between expenditures and revenues in the budget constraint, we can write

$$
\mathbb{Z}_{t}^{r}=\mathbb{R}_{t}^{r},
$$

where each matrix consists of individual expenditure sources $\mathbb{Z}_{t}^{l}$ and individual revenue sources $\mathbb{R}_{t}^{\varpi}$. Mathematically

$$
\begin{gathered}
\mathbb{Z}_{t}^{r}=\sum_{l=1}^{n}\left(\mathbb{Z}_{t}^{r}\right)^{l}, \\
\mathbb{R}_{t}^{r}=\sum_{\varpi=1}^{n} \omega^{\varpi}\left(\mathbb{R}_{t}^{r}\right)^{\varpi},
\end{gathered}
$$

where $\omega^{\varpi}$ stands for the share of individual sources of revenue $\varpi$ and $\xi^{l}$ for the shares of individual sources of expenditure $l$. In order to introduce the parameter for the weight of the income effect in the consumption function, we further add both sides of the equation (7) to the power of $1-\sigma_{i}$ and multiply the terms by $1 /\left(1-\sigma_{i}\right)$ to obtain the common constant elasticity of substitution function

$$
\frac{1}{1-\sigma_{i}^{r}}\left(\sum_{l=1}^{n}\left(\mathbb{Z}_{t}^{r}\right)^{l}\right)^{1-\sigma_{i}^{r}}=\frac{1}{1-\sigma_{i}^{r}}\left(\sum_{\varpi=1}^{n} \omega^{\varpi}\left(\mathbb{R}_{t}^{r}\right)^{\varpi}\right)^{1-\sigma_{i}^{r}} .
$$

The idea for the transformation originates in an option of a representative household to choose between various sources of expenditure and from different sources of income. The household views different sources of expenditure and income as substitutes to each other into some degree.

Maximization of the utility function with respect to the budget constraint yields the subsequent extended version of the first order condition for the consumption variable based on the equality $\mathbb{Z}_{t}=\mathbb{R}_{t}$ in the form

$$
\frac{1}{c_{t}^{r}-h C_{t-1}^{r} \frac{1}{u z_{t}}}-\beta h E_{t} \frac{1}{C_{t+1}^{r} u z_{t+1}-h C_{t}^{r}}=\lambda_{t} P_{t}^{c}\left(1+\tau_{t}^{c}\right)\left(\mathbb{R}_{t}^{r}\right)^{-\sigma_{i}^{r}}
$$

where $\lambda_{t}=\frac{\lambda_{t}^{Z}}{P_{t}}$ and

$$
\begin{gathered}
\mathbb{R}_{t}^{r}=B_{t}+S_{t} B_{t}^{*}+\left(1-\tau_{t}^{k}\right)\left[R_{t}^{k} u_{t} K_{t}^{s}+Q_{t}\right]+\left(1-\tau_{t}^{w}-\tau_{t}^{s c}\right) W_{t}^{r} \Lambda_{t}^{r} N_{j, t}^{r}+ \\
\tau_{t}^{b} W_{t}^{b, r}\left(N_{j, t}^{r}-L_{j, t}^{r}\right)+T R_{t}^{r}+P E N_{t}^{r} .
\end{gathered}
$$

This computation to obtain an optimal consumption function incorporates a habit persistence effect. The derivation of the utility function with respect to consumption assimilates the study of Adolfson et al. (2007). The parameter $\sigma_{i}$ stands for the share of the income effect in 
consumption; this parameter differs for divergent age groups $r$. The revenue function in the loglinearized form appears as

$$
\begin{aligned}
& \widetilde{\mathbb{R}}_{t}^{r}=\omega^{b, r} \tilde{B}_{t}+\omega^{b, r *}\left(\tilde{S}_{t}+\tilde{B}_{t}^{*}\right)+\omega^{t_{k}, r} \tau_{t}^{k}+\omega^{k_{s}, r}\left[\tilde{R}_{t}^{k}+\tilde{u}_{t}+\widetilde{K}_{t}^{s}\right]+\omega^{q, r} \widetilde{Q}_{t}+ \\
& \omega^{t n, r} \tau_{t}^{w}+\omega^{t s c, r} \tau_{t}^{s c}+\omega^{n, r}\left(\widetilde{W}_{t}^{r}+g^{r} \widetilde{\Lambda}_{t}^{r}+\widetilde{N}_{t}^{r}\right)+\omega^{n t b, r}\left(\tilde{\tilde{\tau}}_{t}^{b, A}+\widetilde{W}_{t}^{b, r}\right)+\omega^{n, r} \widetilde{N}_{t}^{r}+ \\
& \omega^{l b, r} \tilde{L}_{t}^{r}+\omega^{t r, r} \widetilde{T R}_{t}^{r}+\omega^{p e n, r} \widetilde{P E N}_{t}^{r} \text {, }
\end{aligned}
$$

where the individual weights represent the share of the respective variables in the steady-state on the total revenue for a representative household. These weights enable an introduction of shares for individual income sources into the consumption function with respect to data. The direct dependence of consumption expenditures on income but also on the effects of changes in interest rate assimilates the study of Cambell and Mankiw (1989).

Finally, the differentiated consumption variable over various age cohorts is subject to aggregation in the subsequent form

$$
c_{t}=\left(\sum_{r=1}^{A} c_{t}^{r} \Omega^{r}\right) P O P .
$$

The labor supply in this model respects the maximization of the utility function subject to the budget constraint, which yields heterogenous labor supply of the form

$$
\left(N_{t}^{r}\right)^{\psi_{N}}=\lambda_{t}\left[1-\tau_{t}^{w}-\tau_{t}^{s c}\right] W_{t}^{r}\left(\Lambda_{t}^{r}\right)^{g^{r}}
$$

and the aggregate labor supply equals

$$
N_{t}=\left(\sum_{r=1}^{A} N_{t}^{r} \Omega^{r}\right) P O P .
$$

\subsection{Firm}

The firm sector also assimilates the original study of Aliyev et al. (2014). Individual firms in the model compete on a market dominated by the market structure of monopolistic competition. The production of heterogenous outputs direct the price-setting behavior of companies. The price-stickiness is modelled identically to Aliyev et al. (2014). The only difference in this sector concerns the labor demand function. Labor variable is subject to disaggregation to account for various age groups which also vary in the degree of their respective productivity level $\Lambda_{t}^{r}$. The labor index composed of different age groups is

$$
L_{t}=\sum_{r=1}^{A}\left(\left(\Lambda_{t}^{r}\right)^{g^{r}} L_{j, t}^{r} \frac{\zeta^{r}-1}{\zeta^{r}}\right)^{\frac{\zeta^{r}}{\zeta^{r}-1}} .
$$

The parameter $g^{r}$ signals the importance of the productivity variable.

A representative firm selects an optimal level of labor and capital which minimizes its overall costs. The optimal demand for individual inputs then depends on the minimization of total costs function

$$
T C_{t}=W_{t}\left(1+\tau_{t}^{s c}\right) L_{t}+R_{t}^{k} K_{t},
$$

where a firm in this model has to also pay social benefits for its employees $\tau_{t}^{S c}$; subject to the production function

$$
Y_{t}=K_{t}^{\alpha}\left(z_{t} L_{t}\right)^{1-\alpha},
$$

in which $K_{t}$ labels the capital, $L_{t}$ the labor input and $z_{t}$ overall technological progress.

The optimal demand for labor is

$$
L_{t}^{*}=\left(\frac{R_{t}^{k}}{W_{t}\left(1+\tau_{t}^{s c}\right)}\right)^{\alpha} Y_{t}
$$


and the optimal demand for capital equals

$$
K_{t}^{*}=\left(\frac{W_{t}\left(1+\tau_{t}^{s c}\right)}{R_{t}^{k}}\right)^{(1-\alpha)} Y_{t}
$$

This specification assimilates Aliyev et al. (2014).

Labor demands for individual heterogenous age groups vary in respective wages and productivity levels. To reflect this differentiation, one needs to minimize the total costs rewritten to account for various labor demands

$$
\min \sum_{r=1}^{A} W_{t}^{r} L_{t}^{r}\left(1+\tau_{t}^{s c}\right)+R_{t}^{k} K_{t},
$$

subject to the production function with respect to the labor index

$$
\left.Y_{t}=K_{t}^{\alpha}\left(z_{t} \sum_{r=1}^{A}\left(\left(\Lambda_{t}^{r}\right)^{g^{r}} L_{t}^{r}\right)^{\frac{\zeta^{r}-1}{\zeta^{r}}}\right)^{\frac{\zeta^{r}}{\zeta^{r}-1}}\right)^{1-\alpha} .
$$

Re-arranging the first order condition from this problem results in

$$
L_{t}^{r *}=\left(\frac{W_{t}}{W_{t}^{r}} \frac{1+\tau_{t}^{s c}}{1+\tau_{t}^{s c, r}}\right)^{\zeta^{r}}\left(\frac{\left(\Lambda_{t}^{r}\right)^{g^{r}}}{\Lambda_{t}^{g}}\right)^{\zeta^{r}-1} L_{t} .
$$

\subsection{Labor market}

This model operates in a staggered-wage environment. Labor is assumed to be heterogenous over varying households. Formulation of the wage-setting problem is consistent with the benchmark model. In similarity to the article of Erceg et al. (2000), the wage stickiness is modeled comparable to the price stickiness. Only $1-\xi_{w}$ of households can set their wage optimal at time $t$. The remaining fraction of households set their wage equal to the wage in the previous period

$$
\left(W_{t}^{r}\right)^{1-\theta_{w}}=\xi_{w}\left(W_{t-1}^{r}\right)^{1-\theta_{w}}+\left(1-\xi_{w}\right)\left(W_{t}^{r *}\right)^{1-\theta_{w}} .
$$

A household $j$ selects optimal wage $w_{t}^{*}$ in the wage-staggered environment. Each household supply differentiated labor $N_{j, t}$. The labor bundler anticipates the labor demand by firms $L_{t}$, the labor demand is the constant-elasticity-of-substitution (CES) function of the differentiated labor supply

$$
E_{t}\left(L_{t}^{r}\right)=\left[\int_{0}^{1}\left(N_{j, t}^{r}\right)^{\frac{\theta_{w}-1}{\theta_{w}}} d j\right]^{\frac{\theta_{w}}{\theta_{w}-1}} .
$$

Maximization of the utility function (2) rewritten for time $t+k$ for the household which sets its wage in period $t$ in respect to the intertemporal budget constraint $(3)$, constraints $(25,26)$ and the demand for household's labor given by

$$
N_{j, t}^{r}=L_{t}^{r}\left(\frac{W_{t}^{r}}{W_{j, t}^{r}}\right)^{\theta_{w}}
$$

results in

$$
W_{t}^{r *}=\frac{\theta_{w}}{\theta_{w}-1} \frac{\sum_{n=0}^{\infty}\left(\beta \xi_{w}\right)^{n}\left(N_{t+n}^{r}(j)\right)^{1+\psi_{N}}}{\sum_{n=0}^{\infty}\left(\beta \xi_{w}\right)^{n}\left(1-\tau_{t+n}^{w}\right) \lambda_{t+n} N_{t+n}^{r}(j)} .
$$

Log-linearization of the equation (28) under the assumption of (25) and (26) allows us to compute the final New Keynesian Phillips curve for wages in log-linearized form 


$$
\begin{gathered}
\widetilde{W}_{t}^{r}=\omega_{w w f} \widetilde{W}_{t+1}^{r}+\omega_{w w l} \widetilde{W}_{t-1}^{r}+\frac{\psi_{N}\left(1-\xi_{w}\right)\left(1-\beta \xi_{w}\right)}{p_{w w}} \tilde{L}_{t}^{r} \\
+\frac{\left(1-\xi_{w}\right)\left(1-\beta \xi_{w}\right)}{p_{w w}}\left\{\frac{\tau^{w}}{1-\tau^{w}} \tau_{t}^{w}-\lambda_{t}^{Z}+P_{t}\right\} .
\end{gathered}
$$

The aggregate log-linearized wage depends on the share of individual wages for different ageing groups i.e.

$$
\widetilde{W}_{t}=\left(\sum_{r=1}^{A} \widetilde{W}_{t}^{r} \Omega_{t}^{r}\right) P O P
$$

\subsection{Government}

The last sector which diverges from the original model is the fiscal block. The formulation of the government sector enables us to test impacts of different policy strategies. Government finances its spendings through tax benefits. Government revenues consists of value-added tax (VAT), income tax, social-security benefits and capital tax respectively, hence

$$
G R_{t}=\tau_{t}^{c}\left(P_{t}^{c} C_{t}+G_{t}^{c}\right)+\tau_{t}^{w} \Omega_{t} W_{t} L_{t}+\tau_{t}^{s c} \Omega_{t} W_{t} L_{t}+\tau_{t}^{k}\left(R_{t}^{k} K_{t}+Q_{t}\right) .
$$

All these taxes are assumed to follow simple AR(1) processes. The expenditures of government comprise pensions, non-pension transfers, government spending and unemployment benefits, so

$$
G E_{t}=P E N_{t}+T R_{t}+G_{t}^{c}+\tau_{t}^{b}\left(N_{t}-L_{t}\right) .
$$

The pension level is subject to the rule

$$
P E N_{t}^{r}=\operatorname{rep}_{t}\left[1-\tau_{t}^{w}-\tau_{t}^{s c}\right] W_{t} N_{t} .
$$

In this model, we assume full control of the replacement ratio by government. By other words, the replacement ratio is an exogenous variable. All the shocks in the model follow simple AR(1) processes.

\section{Parameters}

Parameter estimates for the model sections without the household heterogeneity stay consistent with the original study of Aliyev et al. (2014) as one can see in Table 1 below. The remaining parameters are based on data from the Czech Statistical Office (https://www.czso.cz/, accessed 2019-03-30).

Table 1: Parameters for the model

\begin{tabular}{cccccccccccc}
\hline$\mu_{i m}$ & $\mu_{c m}$ & $\theta^{c}$ & $\theta^{c *}$ & $\theta^{i}$ & $\theta^{i *}$ & $\xi^{w}$ & $\xi^{p}$ & $\beta$ & $\lambda_{\pi}$ & $\lambda_{y}$ & $\eta$ \\
0.32 & 0.22 & 0.3 & 0.3 & 0.2 & 0.2 & 0.2 & 0.9 & 0.99 & 1.5 & 0.5 & 0.53 \\
\hline$\theta^{w}$ & $\kappa$ & $\rho$ & $\psi^{N}$ & $\phi_{r}$ & $\delta$ & $h$ & $\omega_{g g c}$ & $\omega_{w}$ & $\omega_{c *}$ & $\alpha_{R}$ & $s_{r}$ \\
2 & 11 & $-\log (\beta)$ & 1.55 & 0.52 & 0.1 & 0.8 & 0.25 & 0 & 0.594 & 0.465 & 1.531 \\
\hline$\sigma^{i}$ & $\xi^{p m}$ & $\xi^{p x}$ & $\Omega^{y}$ & $\Omega^{o}$ & $\Omega^{m}$ & $\Omega^{p}$ & $\sigma^{i, y}$ & $\sigma^{i, m}$ & $\sigma^{i, o}$ & $\sigma^{i, p}$ & $\zeta^{y}$ \\
8.665 & 0.678 & 0.673 & 0.158 & 0.145 & 0.128 & 0.247 & 5.338 & 4.748 & 5.176 & 4.735 & 2.138 \\
\hline$\zeta^{m}$ & $\zeta^{o}$ & $\zeta^{p}$ & $\zeta$ & $g^{y}$ & $g^{m}$ & $g^{o}$ & $g^{p}$ & & & & \\
2.008 & 2.386 & 1.285 & 2 & 1.069 & 1.004 & 1.193 & 0.643 & & & & \\
\hline
\end{tabular}

Source: the authors and the study of Aliyev et al. (2014).

What differs is the introduction of new parameters into the equations of the model which describe the heterogeneity of individual ageing cohorts.

Parameters $\Omega^{r}$ represent share of individual age cohorts $r=y, m, o, p$ on total population. Household budget survey from the Czech Statistical Office provides necessary data. Next, 
parameter $\zeta$ is calibrated to exceed 1 to respect the substitution character between the different types of labor. In the model, the parameter $\zeta^{r}$ signals dependence of individual labor demand functions based on the size of respective wages. Therefore, the weights for $\zeta^{r}$ reflect the share of wages for individual age cohorts. Parameter $g^{r}$ represents the importance of the productivity shock for every age group. The parameter is measured as a share of the marginal product of labor which by assumption roughly corresponds to wage.

The parameter for the income effect $\sigma^{i, r}$, where $r=y, m, o, p$ is estimated with help of a simple regression analysis. The shortage of data on consumption and net income for individual ageing groups which are provided for only six years, limited us to obtain only rough estimates. Individual models were estimated as simple linear regressions to reveal approximate relation between consumption and net income. The data are available from the Household budget survey of the Czech Statistical Office. The parameters reflect the importance of the income effect (dependence of net income for consumption expenditures) relatively to the inter-temporal effect measured by the significance of interest rate (3M Pribor) in the consumption equation.

\section{Technological progress as compensating factor}

This section presents outcome from the model simulations. The hypothesis, technological progress can mitigate the impact of the ageing problem on the welfare in the Czech economy, is the first one subject to testing. The selected parameters for ageing cohorts copy the values from the European Commission (https://ec.europa.eu). The European Commission presents the shares for differently aged cohorts for the year 2018 and projections for the year 2050. The values in between of these years are assumed to follow a linear function in this study. The final parameters are available in Table 2.

Table 2: Share of ageing cohorts over selected years

\begin{tabular}{ccccc}
\hline \multirow{2}{*}{ Year } & \multicolumn{4}{c}{ Share of age cohorts } \\
\cline { 2 - 5 } & Young & Middle & Old & Retired \\
\hline 2019 & 0.158 & 0.145 & 0.1279 & 0.247 \\
2020 & 0.157 & 0.145 & 0.1276 & 0.251 \\
2021 & 0.156 & 0.144 & 0.1272 & 0.255 \\
2022 & 0.155 & 0.144 & 0.1269 & 0.260 \\
2023 & 0.154 & 0.143 & 0.1266 & 0.264 \\
2024 & 0.153 & 0.143 & 0.1263 & 0.269 \\
2025 & 0.152 & 0.142 & 0.1259 & 0.273 \\
2026 & 0.151 & 0.142 & 0.1256 & 0.277 \\
2027 & 0.149 & 0.141 & 0.1253 & 0.282 \\
2028 & 0.148 & 0.141 & 0.1249 & 0.286 \\
2029 & 0.147 & 0.140 & 0.1246 & 0.291 \\
2030 & 0.146 & 0.140 & 0.1243 & 0.295 \\
2031 & 0.145 & 0.139 & 0.1239 & 0.300 \\
2032 & 0.144 & 0.139 & 0.1236 & 0.304 \\
2033 & 0.143 & 0.138 & 0.1233 & 0.308 \\
2034 & 0.142 & 0.138 & 0.1230 & 0.313 \\
2035 & 0.141 & 0.137 & 0.1226 & 0.317 \\
2036 & 0.140 & 0.137 & 0.1223 & 0.322 \\
2037 & 0.139 & 0.136 & 0.1220 & 0.326 \\
\hline
\end{tabular}

Source: the authors.

The results of the model simulations provide values for welfare functions as disaggregated into the chosen ageing groups. The evolution of these functions over the time span of 20 years is visible in Figure 2. This trajectory of the welfare functions would realize if the parameters for the different cohorts stay the same as they were for the year 2018. 
One can quickly notice from Figure 2 a rather increasing trend for all the welfare functions. The welfare series are modelled as non-stationary and as such they reflect technological growth. The level of welfare for a household directly depends on consumption which is a non-stationary time-series on data. The lowest welfare of retirees is a consequence of high dependence of this group's consumption on pensions rather than labor income as only a fraction of retirees continues being active on the labor market. In the model, the Pensions variable depends on wages and replacement ratio. Productivity shock thus does not directly affect pensions, while the same shock directly impacts labor income. This explains the relatively low welfare growth for retirees in times of ongoing non-stationary technological growth.

Figure 2: Welfare functions for individual ageing groups as growth rates (in \%)

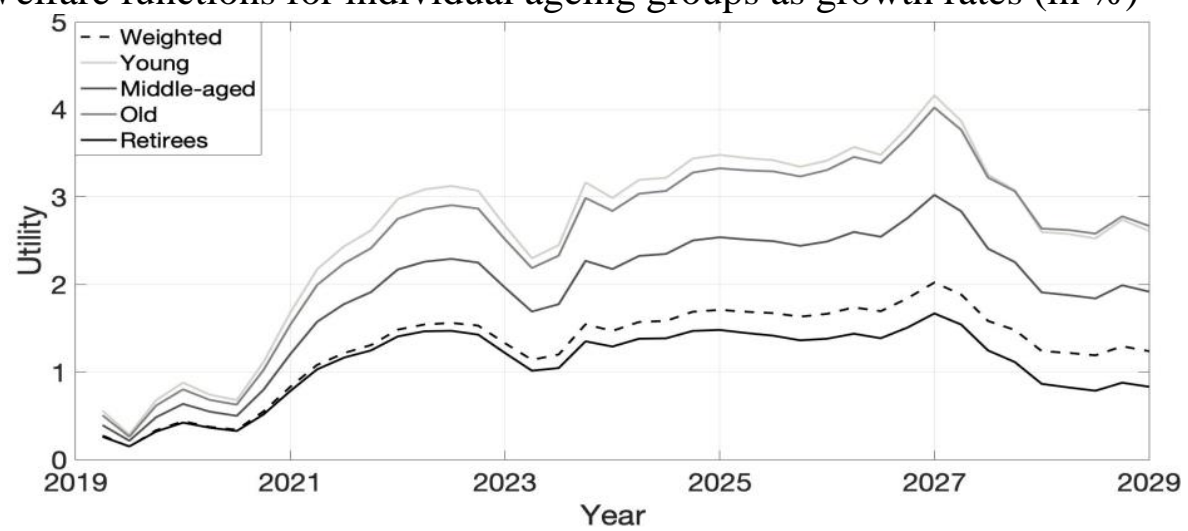

Source: the authors.

In the next exercise, a mathematical algorithm loops the model over varying parameters for the share of individual ageing groups. With the altering demographic distribution towards more significant representation of the retirees, the utility of all ageing groups decreases.

Figure 3 displays the resulting evolution of the utility for the scenario with varying demographic structure (grey line) and for the one where the shares would stay identical as they were in 2018 (black line). One can notice continuing tendency of the line with the varying demographic share calculated from the projections of the European Commission to stay below the line with the constant shares corresponding to the year 2018.

Figure 3: Welfare functions with varying demographic structure as growth rates (in \%)
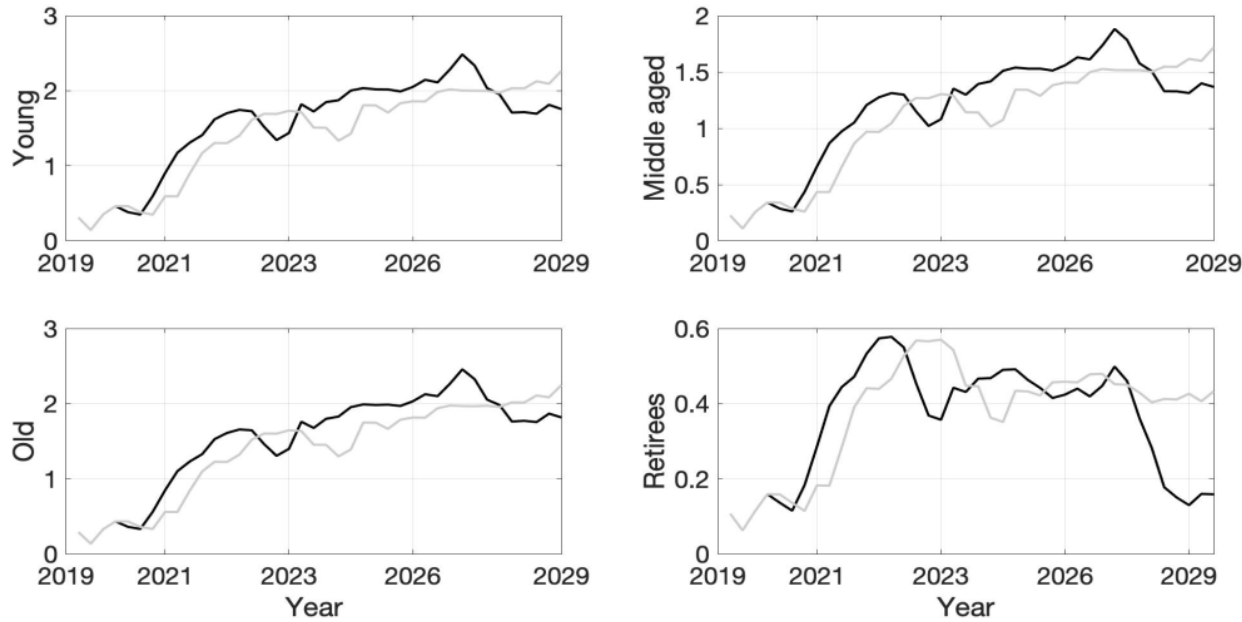

Source: the authors.

The subplots in Figure 4 demonstrate the ageing problem to cause significant heterogeneity for the welfare functions for all the cohorts. 
The straight path for individual lines reflects the linear change in the parameters for the share of ageing cohorts. The increasing share of elderly, with at the same time reduction of younger generations, reduces utility levels for all groups by a significant margin. The retirees represent the least productive group. The lower productivity of these individuals motivates employers to reduce their wage. Competitiveness on the labor market concludes in all wages to be relatively lower. As the share of this rather unproductive cohort magnifies, wages diminish and so thus the aggregate consumption. All cohorts then suffer from the reduction of the economic activity on aggregate. As consequence, consumption of all groups highly dependent on labor income goes down. Utility is predominantly a function of consumption; these interdependencies then result in utility drop for all ageing cohorts. By other words, the size of utility reduction for individual cohorts depends on the sensitivity of their consumption towards wages and the share with which they might affect aggregate variables on the labor market.

Figure 4: Utility sensitivity to varying demographic distribution (in decimal numbers)
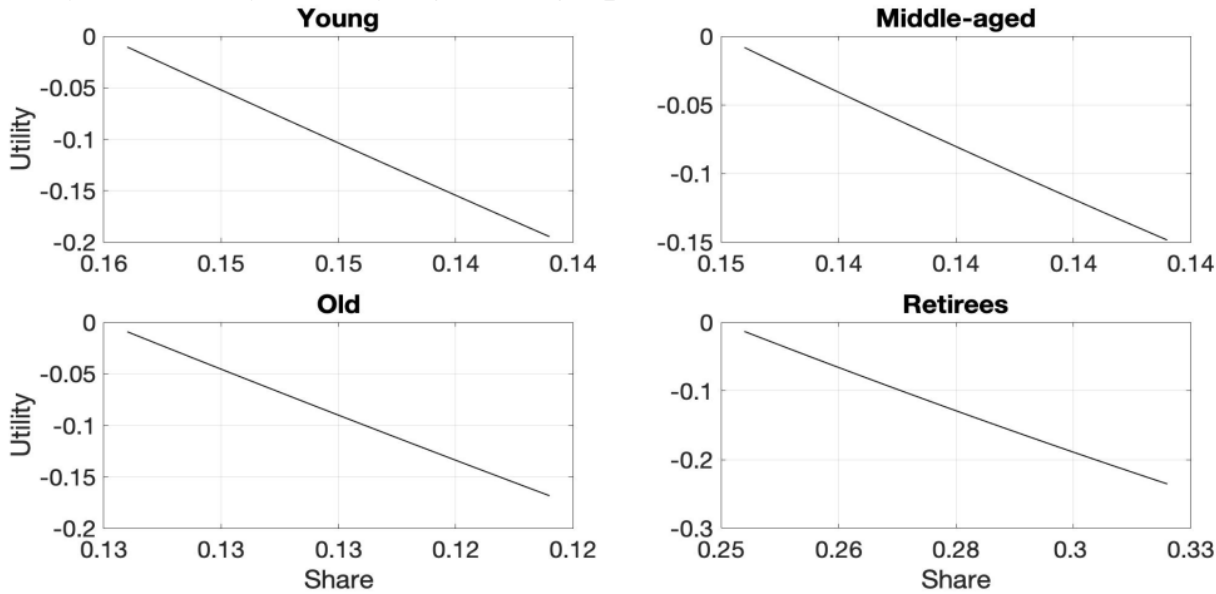

Source: the authors.

After calculating the sensitivity of welfare functions for individual age groups to the changes of demographic structure, we proceed to simulate the size of the technology progress necessary to compensate for such welfare reduction. The simulation procedure called conditional forecasts enables to supplement individual utility variables by specific values. These values were previously simulated as responsiveness of welfare levels to varying demographic structure. Conditional forecast method then operates with the pre-determined values and estimates the necessary size of the individual productivity shocks to maintain the utility level unchanged by the ageing phenomenon.

The first column in Table 3 presents the levels of technological progress required for the aggregate welfare level to maintain unaltered. In order to calculate values for the other columns, we introduce differentiated productivity shocks for individual age cohorts in the model. Such higher detail enables us to simulate the required productivity level for individual age groups in order for the cohorts' respective levels of welfare to stay same in presence of the demographic shifts.

Based on the simulation outcome, the retirees can maintain their utility constant only if their productivity level starts to significantly grow. This result reflects the low share of the wage variable in the consumption function for pensioners, which is measured by the respective steady-states. By other words, the productivity level must grow even more to support the subsequent boom of wages when wages represent only small fraction of the households' income. The remaining generations suffer from their declining shares on total population. Next, these age groups are also negatively affected by the growth of the number of retirees which are less productive which in turn pressures aggregate wage level. 
Table 3: Level of technological progress necessary to maintain current welfare level (in \%)

\begin{tabular}{|c|c|c|c|c|c|}
\hline \multirow{2}{*}{ Year } & \multicolumn{5}{|c|}{ Progress } \\
\hline & Total & Young & Medium & Old & Retirees \\
\hline 2019 & 0.1 & 0.1 & 0.1 & 0.1 & 0.5 \\
\hline 2020 & 0.2 & 0.3 & 0.3 & 0.3 & 1.8 \\
\hline 2021 & 0.5 & 0.6 & 0.7 & 0.5 & 3.7 \\
\hline 2022 & 0.8 & 1.0 & 1.1 & 0.9 & 5.9 \\
\hline 2023 & 1.3 & 1.5 & 1.6 & 1.3 & 8.4 \\
\hline 2024 & 1.8 & 2.0 & 2.1 & 1.7 & 11.1 \\
\hline 2025 & 2.3 & 2.5 & 2.7 & 2.2 & 13.8 \\
\hline 2026 & 3.0 & 3.1 & 3.2 & 2.6 & 16.7 \\
\hline 2027 & 3.7 & 3.6 & 3.8 & 3.1 & 19.6 \\
\hline 2028 & 4.4 & 4.2 & 4.3 & 3.6 & 22.6 \\
\hline 2029 & 5.3 & 4.8 & 4.9 & 4.1 & 25.5 \\
\hline 2030 & 6.1 & 5.4 & 5.4 & 4.6 & 28.5 \\
\hline 2031 & 7.0 & 6.0 & 6.0 & 5.1 & 31.4 \\
\hline 2032 & 7.9 & 6.6 & 6.6 & 5.6 & 34.4 \\
\hline 2033 & 8.9 & 7.2 & 7.1 & 6.1 & 37.3 \\
\hline 2034 & 9.9 & 7.8 & 7.7 & 6.6 & 40.2 \\
\hline 2035 & 11.0 & 8.4 & 8.2 & 7.1 & 43.1 \\
\hline 2036 & 12.0 & 9.0 & 8.7 & 7.6 & 46.0 \\
\hline 2037 & 13.1 & 9.6 & 9.3 & 8.1 & 48.9 \\
\hline
\end{tabular}

Source: the authors.

\section{Government expenditures as compensating factor}

This section analyzes a potential of the government sector to balance the simulated decline in welfare level over time. First, we analyze necessary level for a replacement ratio which would lead to unaltered welfare functions irrespective the ageing phenomenon. The replacement ratio is assumed to be an exogenous variable and as such can be analyzed via conditional forecast. Values for utility functions given the altering share of age cohorts are obtained from the previous iteration exercise. Conditional forecast then takes the values for the welfare functions as given and calculates necessary level for the replacement ratio to keep the utility values unchanged.

The first column in Table 4 presents the required values for the replacement ratio to keep the aggregate utility level constant. The results suggest a significant increase in the replacement ratio by more than three times by the end 2037 for the welfare levels to stay same.

The next interesting question is to analyze the level of social security which would compensate the gap in government balance. This government balance decline is a consequence of the demographic shifts. First, the ageing of population induces higher share of fiscal spending to go towards old pensions plus the government revenue declines as the ageing phenomenon causes deterioration of aggregate economic activity. Second, we calculate the size of the government deficit as a consequence of the increased replacement ratio, which growth was previously simulated to compensate the impact of demographic changes on individuals' wellbeing. The sum of these sources produces total government balance reduction in the scenario where government compensate the welfare decline by the growth of the replacement ratio. The results are present on the third column of Table 4.

Social security payments are significant sources of government revenue and as such they could compensate the government deficit caused by the growing replacement ratio which keeps the constant welfare level. The last column in Table 4 supplies the values for the required elevation of the social security payments in order to maintain balanced government budget in the situation where the replacement ratio compensates the welfare drop in the economy. 
Table 4: Replacement ratio necessary to keep current welfare level (in \%)

\begin{tabular}{cccc}
\hline \multirow{2}{*}{ Year } & \multicolumn{3}{c}{ Replacement ratio } \\
\cline { 2 - 4 } & Rep. ratio & Gov. balance & Social security \\
\hline 2020 & 41.23 & -5.32 & 6.38 \\
2021 & 60.72 & -7.35 & 9.09 \\
2022 & 80.97 & -9.26 & 11.65 \\
2023 & 99.44 & -10.84 & 13.78 \\
2024 & 118.51 & -12.38 & 15.83 \\
2025 & 136.98 & -13.78 & 17.72 \\
2026 & 153.76 & -14.88 & 19.28 \\
2027 & 171.14 & -16.00 & 20.81 \\
2028 & 187.98 & -17.02 & 22.19 \\
2029 & 204.33 & -17.90 & 23.46 \\
2030 & 220.21 & -18.68 & 24.52 \\
2031 & 236.68 & -19.48 & 25.62 \\
2032 & 251.66 & -20.03 & 26.43 \\
2033 & 266.22 & -20.49 & 27.08 \\
2034 & 280.38 & -20.86 & 27.62 \\
2035 & 295.12 & -21.27 & 28.23 \\
2036 & 308.49 & -21.47 & 28.56 \\
2037 & 322.00 & -22.00 & 29.00 \\
\hline
\end{tabular}

Source: the authors.

\section{Conclusion}

This model proves a significant impact of the ageing phenomenon on the level of welfare in the Czech economy. The projected demographic shifts by the European Commission would affect the level of welfare for all ageing groups. Steadily increasing technological progress could compensate for the reduction of welfare for the individual ageing cohorts. With the exception of the retirees whose share is expected to grow by about 1.5 percent every year, the representation of the remaining age groups is expected to drop by about 0.5 percent annually. The utility level would in turn continuously decline for all the studied groups. In 20 years, the utility level of all cohorts would be lower by about 20 percent. The productivity would need to grow by around 30 percent for the retirees and by 10 percent for the other groups in 20 years, for the utility functions to maintain their current level.

Fiscal policy-makers are capable on their own to affect the consequences of the ageing phenomenon. Relatively sizable increase in replacement ratio would maintain the current welfare in the Czech economy. The consequent growth of pensions and in turn government spending could be equalized by higher social security payments. The social security payments would need to raise by around 20 percent per year to overcome government deficit caused by the ageing.

This study proves significant variations of the model results subject to ageing phenomenon. Policy makers can apply it to analyze various scenarios concerning economic impacts of demographic shifts such as impact-evaluation of different pension schemes but also to assess demographic projections.

\section{Acknowledgements}

The paper was supported by the grant scheme GAČR No. 19-03984S "Economy of successful ageing". 


\section{References}

[1] Adolfson, M. et al. 2007. Bayesian estimation of an open economy DSGE model with incomplete pass-through. In Journal of International Economics, 2007, vol. 72, iss. 2, pp. 481-511.

[2] Aliyev, I., Bobková, B., Štork, Z. 2014. Extended DSGE model of the Czech economy. Ministry of Finance of the Czech Republic, 2014. [cit. 2019-03-22] https:// www.mfcr.cz/cs/ o-ministerstvu/odborne-studie-a-vyzkumy/2014/rozsireny-dsge-model-c eske-ekonomiky-17282.

[3] Babecký, J., Dybczak, K. 2009. The impact of population ageing on the Czech economy. Prague : Czech National Bank, Research Department, 2009. [cit. 2019-03-22] https:/ /core.ac.uk/download/pdf/6404662.pdf.

[4] Benjamin, D. J. et al. 2012. Beyond happiness and satisfaction: toward well-being indices based on stated preference. Working Paper No. 18374. Cambridge : National Bureau of Economic Research, 2012.

[5] Braz, C. et al. 2013. Ageing and fiscal sustainability in a small euro area economy. Lisabon : Banco de Portugal, Economics and Research Department, 2013. [cit. 2019-03-22] https://www.bportugal.pt/sites/default/files/anexos/papers/wp201304.pdf.

[6] Campbell, J. Y., Mankiw, N. G. 1989. Consumption, income, and interest rates: reinterpreting the time series evidence. In NBER Macroeconomics Annual, 2013, vol. 4, pp. 185-216.

[7] Coenen, G., Straub, R. 2005. Does government spending crowd in private consumption? Theory and empirical evidence for the Euro Area. In International Finance, 2005, vol. 8, iss. 3, pp. 435-470.

[8] Copaciu, M., Nalban, V., Bulete, C. 2015. R.E.M. 2.0, an estimated DSGE model for Romania. Dynare Working Papers. Paris : CEPREMAP, 2015. [cit. 2019-03-23] https:// ideas.repec.org/p/cpm/dynare/048.html.

[9] Erceg, C. J., Henderson, D. W., Levin, A. T. 2000. Optimal monetary policy with staggered wage and price contracts. In Journal of Monetary Economics, 2000, vol. 46, pp. 281-313.

[10]Fleurbaey, M. 2009. Beyond GDP: The quest for a measure of social welfare. In Journal of Economic Literature, 2009, vol. 47, iss. 4, pp. 1029-1075.

[11] Kilponen, J., Kinnunen, H., Ripatti, A. 2006. Population ageing in a small open economy - some policy experiments with a tractable general equilibrium model. Research Discussion Paper 28/2006. Helsinki : Bank of Finland, 2006.

[12] Roeger, W., Varga, J., Veld, J. in't, 2008. Structural reforms in the EU: A simulation-based analysis using the QUEST model with endogenous growth. Economic Papers 2008 - 2015, No. 351. Luxembourg : Directorate General Economic and Financial Affairs (DG ECFIN), European Commission, 2008. 